EPiC Series in Language and Linguistics
Volume 3, 2018, Pages 12-18
LSP in Multi-disciplinary contexts of
Teaching and Research. Papers from the
16th International AELFE Conference

\title{
English as a lingua franca on the International Campus of Excellence: Initiatives and outcomes
}

\author{
Ana Bocanegra-Valle \\ Universidad de Cádiz. Área de Filología Inglesa. CASEM. Campus Universitario. 11510 Puerto Real (Cádiz), Spain
}

\begin{abstract}
This paper draws on two policy documents, the "International Campus of Excellence Initiative" and the "University Strategy 2010-2015" to assess the level of internationalisation of the Spanish university system as portrayed by the international campuses of excellence (ICEs). It sets out to identify the role and use of English as a lingua franca with academic purposes across Spanish ICEs and the initiatives developed based on the use of English as a communication tool in this academic context. The investigation draws on textual data gathered from the websites of two Spanish-based ICEs, such as Ceimar (ICE on Marine Science) and Iberus (ICE of the Ebro Valley). The website analysis shows that these two ICEs rely on English to implement issues of internationality in their academic offer and articulate a diversity of actions and programmes in which English is used as the lingua franca for international communication and academic teaching as well as for the dissemination of research activities.
\end{abstract}

Keywords: English as a lingua franca; Academic English, Internationalisation; International Campus of Excellence.

\section{Introduction}

European universities have been facing many challenges during the last decade to match the requirements of the European Higher Education Area (EHEA). One relevant example is the International Campuses of Excellence (ICEs), developed to foster the modernisation and internationalisation of universities and create "knowledge hubs" between universities or between these and other private or public bodies (European Union, 2016). Particularly in Spain, the Secretariat-General of Universities, under the Ministry of Education, launched the "International Campus of Excellence Initiative" as one of the main outcomes of its policy framework "University Strategy 2010-2015" (Ministerio de Educación, 2011; European Union, 2016; Seeber, 2017). One of the main goals of this Initiative was "to increase internationalisation and attractiveness for international students, academics and knowledge-related investors by encouraging international mobility, articulating an international academic offering and recruiting international faculty" (European Union, 2016: 5; cf. Rubiralta \& Delgado, 2010). This paper focuses on these two policy documents (the Initiative and the Strategy) to capture some first insights into the level of internationalisation of the Spanish university system as portrayed by the international campuses. More particularly, it sets out to examine the role and use of English as a 
lingua franca with academic purposes across Spanish ICEs and the initiatives developed to promote the use of English as a communication tool in this academic context. The investigation draws on textual data gathered from the websites of two relevant and rather different ICEs, such as Ceimar (ICE on Marine Science) and Iberus (ICE of the Ebro Valley).

\section{Background}

\subsection{The University Strategy 2010-2015}

The University Strategy 2010-2015 (US15 henceforth) was adopted by the Spanish Council of Ministers on 25 June 2010 as a response to the need for the improvement of higher education in Spain and in pursuance of the European Union's recommendations regarding the modernisation agenda for universities against competitiveness in a global knowledge economy (Ministerio de Educación, 2011). The US15 lays down four main objectives towards the effective internationalisation of universities: (i) to develop a highly internationalised university system; (ii) to raise the international appeal of Spanish universities; (iii) to deepen the social dimension and responsibility in response to society's global challenges; and (iv) to intensify cooperation with other regions on a longer term. It is particularly this fourth objective (that is to say, the need for institutional relations, open cooperation and alliances among institutions) that has encouraged the creation of international campuses of excellences (ICEs). Also, the drive to supporting national interests against an internationally competitive research context has led to the establishment of ICEs as one of the most relevant initiatives underpinning internationalisation policies. As stated in the US15, the ICEs are a key factor in the modernisation process of higher education whose goals are "to make Spanish universities more competitive on the global level, more prestigious and better known, and thereby to improve the quality of the entire Spanish university system" (Ministerio de Educación, 2011: 172).

\subsection{The International Campus of Excellence Initiative}

ICEs are key to promoting the stronger specialisation of universities, fostering strategic aggregation to industry and strengthening internationalisation, research and innovation. The International Campus of Excellence Initiative (ICEI), developed under the tenets of the US15, pursued six general aims, as summed up by Rubiralta and Delgado (2010; cf. also European Union, 2016): (i) to reduce fragmentation and atomisation of higher education and its research system; (ii) to reduce isolation of universities; (iii) to increase the diversity of courses and research; (iv) to make universities more attractive to international students and staff; (v) to improve university governance; and (vi) to raise the levels of excellence and efficiency in higher education teaching and research. Since the ICE programme was first launched in Spain in 2009, 32 CEIs (16 general CEIs plus 15 CEIs of Regional Interest) involving 63 universities have been created and developed with an aggregate budget of 688 million euros (European Commission, 2017). As reported in the conclusion document published by the European Union (2016), thanks to the ICEI, universities have raised their internationalisation levels with regard to teaching (because more English/Spanish bilingual courses are being offered) and research (because international scientific collaborations have increased by $12 \%$ between 2009 and 2014). 


\section{Methodology}

\subsection{Research aims}

This study aimed to examine the role and use of English as a lingua franca with academic purposes across Spanish ICEs and the initiatives developed to promote the use of English as a communication tool in this academic context.

\subsection{Data}

This investigation draws on textual data gathered from the websites of two relevant and rather different ICEs, such as Ceimar (ICE on Marine Science) and Iberus (ICE of the Ebro Valley). Ceimar ( $<$ http://www.campusdelmar.com/en/ceimar-en/>) is a cross-border ICE, created in 2011 and made up of four Spanish universities in the Andalusian region (University of Granada, University of Huelva, University of Almería, and University of Málaga), one Portuguese university (Algarve), one Moroccan university (Abdelmalek Essaâdi), and seven regional marine research-related institutions (like the Spanish Oceanographic Institute or the Royal Institute and Observatory of the Spanish Navy). The main areas covered by Ceimar are related to the study of the sea from the perspectives of science, engineering and humanities, and deal with topics from marine environment to underwater archaeology, including the shipping and the shipbuilding industries, the sea as portrayed in the literature or in the cinema, marine life or marine pollution, among others. Iberus ( $<$ http://www.campusiberus.es/?lang=en $>$ ) is the ICE of the Ebro Valley. It was created in May 2012 and comprises four universities from four regions in Spain: the University of Zaragoza (in Aragón), the University of La Rioja (in La Rioja), the Public University of Navarra (in Navarra) and the University of Lleida (in Catalonia). The main areas covered by Iberus are four: sustainable energy (energies and the environment); health technologies; nutrition, agriculture and food; and cultural heritage preservation. Among its many objectives, Iberus aims at backing internationalisation "based on mobility, attracting students and researchers, promoting the international c.v., international strategic agreements and increasing visibility" - for full details and reflections on Iberus as an example of ICE see Seeber (2017).

\section{Findings and discussion}

A detailed examination of the two target websites shows that both ICEs are concerned with two broad themes in which the use of English as a lingua franca is involved. These are (i) issues of internationality and (ii) English for academic purposes and English-medium instruction. Each of these entails other sub-themes as explained below.

\subsection{Issues of internationality}

Internationality spreads across both ICEs and comprises three main sub-themes: the use of English as a lingua franca for communication, participation in international projects, and a wide offer of mobility and internship programmes.

\subsubsection{English as a lingua franca for communication}

Both Iberus and Ceimar provide websites in English versions - a French version is also provided by Iberus. These websites duplicate the information which is available on the main 
Spanish sites. If both ICE's websites are compared, Ceimar provides a more complete account of all activities in English and both main and sub-sections contain English information. Iberus, on the contrary, is not consistent when providing information in English, as some hyperlinks are only apparently linked to information in English and this is inconsistently provided throughout.

\subsubsection{International projects}

The development of international project and cooperation initiatives are key to both ICEs.

For the purpose of attaining the highest level of efficiency and the highest number of European research projects under the Horizon 2020 Scheme, all Spanish universities within the scope of Ceimar together with the University of Algarve have a "European Project Office". It stands out that there is a branch office of Ceimar located in the Andalusian Government headquarters in Brussels. The aim of this international office is to assist researchers when travelling to the city for group work meetings and, most importantly, to provide them with support when looking for project partners and developing European projects initiatives of any kind - particularly those headed by the European Council in connection with the Blue growth strategy in innovation (see $<$ http://ec.europa.eu/transparency/regdoc/rep/1/2013/EN/1-2013-279-EN-F1-1.Pdf >). Iberus also has a branch office in Brussels, which is a part of the Research Council's (CSIC) headquarters. With this office, Iberus and Ceimar pursue similar general aims and pay particular attention to all those issues pertaining to R\&D\&I initiatives such as knowledge and innovation communities, joint technology, and innovation partnerships. Particularly relevant to Iberus is the "Cross-border Campus Project" which aims at closer cooperation with French universities in terms of common infrastructure and resources, knowledge transfer activities, mobility programmes for staff and students, and joint partnerships, programmes and entrepreneur organisations. Also, as a member of the European Energy Research Alliance (EERA), Iberus actively participates in the Joint Programmes "Bioenergy" and "Smart Cities", the "Bio-based Industries Consortium" with a view to "internationally boost its researcher dimension" within the EU Strategy Energy Technology Plan (see http://www.uca.es/es/tratarAplicacionUnidades.do?idColectivo=3).

\subsubsection{Mobility and internship programmes}

Ceimar offers thirty students the possibility of completing an Erasmus + internship programme in seven different countries (France, The Netherlands, Germany, Belgium, Hungary, United Kingdom, and Portugal). It also provides graduates and doctoral students with Erasmus+ mobility programmes for universities in France, Italy, Romania, The Netherlands, Latvia, Portugal, Poland, Germany, United Kingdom and Hungary. In the same vein, Iberus offers mobility programmes for staff and students and, particularly, a wider variety destination for the Erasmus+ internship programme as almost all European countries participate for periods of three months. For Iberus, one of the main aims of these programmes is to offer an opportunity for "promoting language proficiency (...) at an international level" and "in an increasingly global world" - however, it is not explicitly stated that such working language should be English. Unlike Ceimar, Iberus offers an "International mentor programme" with a view to promote the academic and scientific power of their universities; thanks to this programme eight post-graduate students can complete a research stay in the USA for 6-8 weeks' periods. Hopefully, such stays will help students, among others, to improve their English language level. 


\subsection{English-medium instruction and English for academic purposes}

The instruction of content knowledge through the English language (i.e. English-medium instruction, or EMI henceforth) aims at all students' levels and embraces three main groups of activities: doctoral schools, conferences of excellence and summer schools.

\subsubsection{Doctoral Schools}

The International Doctoral School in Marine Studies offered by Ceimar provides a full programme with different courses on marine science and technology, resources, history, management and archaeology supported by 225 researchers from 21 institutions in 13 countries. The School was also joined by the Doctoral Erasmus Mundus programme on Marine and Coastal Managements and brought along the participation of five universities from Portugal, Italy, Russia and Spain. Among the twelve courses offered, one of them "Practical marine ecotoxicology: novel approaches" is fully delivered in English. An interesting issue at this point is the number of $\mathrm{PhD}$ dissertations (seven out of ten) that were fully written and presented in English in the past two years. Unlike Ceimar, the offer of EMI or the presentation of $\mathrm{PhD}$ dissertations in English is missing from Iberus' website. An interesting issue, however, is the need for doctoral students to write "at least an article in the language of the research discipline", which, particularly in the case of science and technology, might covertly mean English.

\subsubsection{Lectures of excellence}

Ceimar offers "Lectures of excellence" in situ at any of the ICE's locations and via web to the remaining locations. Then, they are made available on line at Ceimar's YouTube channel via the main website so that students can follow the lecturer with greater detail. Even though some of these Lectures are delivered in Spanish, most of them (so far six out of eight) have been delivered in English by reputed foreign scholars (e.g. "The power of studies on zebrafish: translational values for fish aquaculture and comparative physiology").

\subsubsection{Summer schools}

EMI is also present across Summer school tuition. Iberus Business Summer School is aimed at "Chinese undergraduates in their final year or those recently graduated who have a businessoriented profile and are interested in studying the entrepreneurial and cultural environments of Spain". An explicit requirement for students is to be aware of the fact that "[a]11 teaching will be conducted in English" - thus, EMI prevails. In this Business course, students study at different locations within the ICE and are expected to be trained in the practical skills and knowledge that are required to develop an international business plan. They will also be required to present such plan in English to a learned audience (academics and other students); however, from the information available on the website, there does not seem to be any additional courses aiming to provide such training (i.e. English for Academic Purposes courses). Unlike Iberus, Ceimar is aimed at undergraduate and graduate students from any university worldwide and lecturers come from Spanish and international universities and research centres. Courses take place in three locations: Cádiz and Granada, in Spain, and Faro, in Portugal. Seven courses are offered, six of them are EMI courses. Among them, "Effective communication skills for scientists" aims at covering the need for academic English knowledge and skills, and fills the gap of academic English training. Very briefly, this course offers students the opportunity to learn about abstract 
and article writing, the design and presentation of posters at scientific events, the development of oral presentations with the use of computer tools and, most importantly, the ways to give a good oral presentation at a conference or workshop. The whole course is implemented in English and taught by both Spanish and Dutch experienced lecturers.

\section{Concluding remarks}

Iberus and Ceimar's initiatives are in line with the two key components in the internationalisation strategy of the European Commission - that is, "internationalisation at home (IaH)" and "internationalisation abroad" (European Parliament, 2015). On the one hand, the two campuses have developed good practices in terms of IaH, that is to say, more curriculumorientated and particular focus placed on "activities that develop international or global understanding and intercultural skills" (European Parliament, 2015: 45). Examples of this are the Lectures of Excellence, the writing of PhD dissertations in English, the Iberus Business Summer School or the academic English course offered by Ceimar Summer School. On the other hand, both campuses have endeavored to provide education and support research across borders - that is, to develop their best internationalisation abroad practices. Examples of this are their branch offices in Brussels or the number and diversity of mobility and internship programmes that both ICEs offer. Iberus and Ceimar's initiatives and outcomes towards internationality might also be understood in terms of "institutional internationalisation" and "student-focused internationalisation" (Jones, 2010). This indicates that both the institution and the student are strongly placed at the centre of ICE's internationalisation strategy.

It has not been the intention of this study to identify similarities and differences between the two target campuses, Ceimar and Iberus, but to explore the role of English as a lingua franca in the international offer of two Spanish-based ICEs. It is also important to note that this analysis is based on the textual data available on the ICEs' websites. The analysis shows how Ceimar and Iberus have made use of English to implement issues of internationality in their academic offer and articulate a diversity of actions and programmes in which English is used as the lingua franca for international communication, academic teaching and dissemination of research activities. However, as examples attest, very little has so far been done to assist lecturers, researchers and students in their English language needs in this context.

\section{Acknowledgements}

This work is a contribution to national research project FFI2015-68638-R MINECO/FEDER, EU, funded by the Spanish Ministry of Economy and Competitiveness.

\section{References}

\footnotetext{
European Commission (2017). International Campus of Excellence (CEI). Retrieved from http://ec.europa.eu/education/compendium/international-campus-excellence-cei_en

European Parliament (2015). Internationalisation of Higher Education. Brussels: Directorate-General for Internal Policies. Retrieved from http://www.europarl.europa.eu/RegData/etudes/STUD/2015/540370/IPOL_STU(2015)540370_EN.pdf

European Union (2016). Spain, the International Campus of Excellence Initiative. Retrieved from http://bookshop.europa.eu/en/spain-the-international-campus-of-excellence-initiative-pbNC0116162/

Jones, E. (Ed.) (2010). Internationalisation and the student voice: Higher education perspectives. London: Routledge.
} 
Ministerio de Educación (2011). Estrategia Universidad 2015. The contribution of universities to Spanish socioeconomic progress 2010-2015. Retrieved from https://sede.educacion.gob.es/publiventa/d/14276/19/0

Rubiralta, M., \& Delgado, L. (2010). Developing international campuses of excellence in Spain. CELE Exchange 2010/4: 1-5.

Seeber, M. (2017). The International Campus of Excellence Initiative in Spain. In J. F. Harry de Boer, J. Huisman, M. Seeber, M. Vukasovic, \& D. F. Westerheijden (Eds.), Policy Analysis of Structural Reforms in Higher Education. Processes and Outcomes (pp. 183-201). London: Palgrave Macmillan. 